\title{
Anti-Fibrotic Potential of Nicorandil in the Treatment of Bleomycin Induced Pulmonary Fibrosis
}

\author{
Sandip Patel ${ }^{1 *}$, Nidhi Patel ${ }^{2}$, Veena Patel ${ }^{3}$ \\ 'Department of Pharmacology, Ramanbhai Patel College of Pharmacy, CHARUSAT, Changa, Petlad, Anand-388421, Gujarat. INDIA. \\ ${ }^{2}$ Department of Pharmacology, A.R. Patel and G.H. Patel Institute of Pharmacy, Vallabh Vidyanagar, Anand-388120, Gujarat. INDIA. \\ ${ }^{3}$ Department of Pharmacognosy, Anand Pharmacy College, Anand-388001, Gujarat. INDIA.
}

\begin{abstract}
Objective: The current study aimed to investigate the possible protective action of Nicorandil in the rat model of Bleomycin induced lung fibrosis. Method: Pulmonary fibrosis was induced by intra-tracheal administration of $0.1 \mathrm{ml}$ of Bleomycin hydrochloride $(5 \mathrm{mg} / \mathrm{kg}$ in $0.9 \% \mathrm{NaCl}$ ) to wistar albino rats (250-300 g; $n=6$ per group). Control rats received an equal volume of saline intra-tracheal route. In the treatment groups, the rats were treated with Nicorandil ( $5 \mathrm{mg} / \mathrm{kg}$ per day; subcutaneously) for 28 days. Another group of rats were administered subcutaneously with Sildenafil Citrate $(10 \mathrm{mg} / \mathrm{kg})$. Blood was collected from retro-orbital plexus for the assessment of serum Lactate Dehydrogenase (LDH) levels. Broncho-alveolar Lavage fluid (BALF) was collected and evaluated for total and differential cell count. After decapitation, the lungs were excised and taken for microscopic evaluation or stored for the measurement of Glutathione (GSH), Catalase (CAT), Superoxide Dismutase (SOD), Nitric Oxide (NO) and lung parameters like Hydroxyproline content. Results: Nicorandil significantly decreased the Hydroxyproline content, a marker of collagen index, supporting its role in preventing Pulmonary Fibrosis. Also, the levels of total and differential cell count were found to decrease showing prevention of cell damage. The
\end{abstract}

protective role was evident by the reduced levels of LDH and MDA, markers of cell damage as well as increased levels of SOD, CAT, GSH and NO. Conclusion: $K_{\text {ATP }}$ channel activation may play an important role in the protective effect of nicorandil against bleomycin induced pulmonary fibrosis.

Key words: Nicorandil, Potassium Channel, Bleomycin, Pulmonary Fibrosis, Oxidative Stress.

Key messages: Anti-fibrotic potential of Nicorandil

Correspondence :

Dr. Sandip B. Patel, Department of Pharmacology, Ramanbhai Patel College of Pharmacy (RPCP), Charotar University of Science and Technology (CHARUSAT), Changa, Petlad, Anand, Gujarat, INDIA.

Cell: 9428479583

Email: sandippatel.ph@charusat.ac.in

DOI: 10.5530/jyp.2017.9.75

\section{INTRODUCTION}

Bleomycin is an anti-cancer agent with limited therapeutic use in the clinics due to its toxicities. Bleomycin-induced pulmonary fibrosis is a widely used animal model of idiopathic pulmonary fibrosis. Intratracheal administration of Bleomycin into the lungs of the rats has shown to cause alveolar damage, fibroblast proliferation, inflammatory cell accumulation and collagen deposition all of which contribute to the development of lung fibrosis. The reactive oxygen metabolites were found to have a significant role in the development of lung injury in this model. Indeed, several observations demonstrated that anti-oxidant regimen including $\mathrm{N}$-acetylcysteine and erdosteine attenuated the extent of tissue injury. Moreover, excess nitric oxide production was also shown to be involved in the Bleomycin induced toxicity in rats. ${ }^{1}$

Potassium channels modifying membrane potential and, consequently, the activation of voltage-gated calcium ion channels, are important target proteins highly expressed on neural structures, epithelial cells and smooth airways muscles. ${ }^{2}$ They are also known as important effectors element for several relaxant agents in the guinea pig isolated trachea, like nitric oxide and VIP. ${ }^{3}$ Nicorandil is a unique hybrid vasodilator and exerts two vasodilator actions; adenosine triphosphate (ATP)-sensitive potassium $\left(\mathrm{K}_{\mathrm{ATP}}\right)$ channel opening and nitric oxide $(\mathrm{NO})$ release. ${ }^{4}$ Earlier, it was reported that Nicorandil attenuated the monocrotaline induced endothelial damage and pulmonary arterial hypertension through the production of endothelial NO synthase (eNOS) and anti-apoptotic factors. These effects of nicorandil were closely associated with the enhanced expression of eNOS and anti-apoptotic factors in the vascular endothelium of the lungs, while those were blocked by glibenclamide and L-NAME, suggesting that the beneficial effects of nicorandil on pulmonary vasculature are mediated by the opening of $\mathrm{K}_{\text {ATP }}$ channels and NOS. ${ }^{5}$ It is also an established fact that Nicorandil exerts its major effects attributing to potassium channel opening and with adjunctive NO releasing property. This unique feature of nicorandil which is already used in the treatment of pulmonary arterial hypertension was used as a basis to hypothesise its additional use in pulmonary fibrosis.

In the light of the above-mentioned findings, this study aimed to investigate the possible protective effect of Nicorandil on the extent of tissue integrity, oxidant-antioxidant status in experimental rat model of Bleomycin induced lung fibrosis.

\section{MATERIALS AND METHODS}

\section{Animals}

Adult Wistar albino rats of either sex weighing 250-300g were housed in polypropylene cages and maintained under conditions of temperature $\left(25^{\circ} \mathrm{C} \pm 1{ }^{\circ} \mathrm{C}\right)$ and relative humidity $(50 \% \pm 5 \%)$, under a standard light/ dark cycle of $12 \mathrm{~h}$. The animals were provided with a standard pellet diet and water ad libitum. All studies were carried out in accordance with the guidelines provided by the Committee for the Purpose of Control and Supervision of Experiments on Animals, India. The experimental protocol was approved by the Institutional Animal Ethical Committee (CPCSEA/IAEC/ARCP/12-13/07).

This is an open access article distributed under the terms of the Creative Commons Attribution-NonCommercial-ShareAlike 4.0 License, which allows others to remix, tweak, and build upon the work non-commercially, as long as the author is credited and the new creations are licensed under the identical terms. 


\section{Induction of Pulmonary Fibrosis}

After an overnight fasting, lung fibrosis was induced by intra-tracheal administration of $0.1 \mathrm{ml}$ of bleomycin hydrochloride $(5 \mathrm{mg} / \mathrm{kg}$ in $0.9 \%$ $\mathrm{NaCl}$ ) under anesthesia with $60 \mathrm{mg} / \mathrm{kg}$ ketamine hydrochloride and $5 \mathrm{mg} / \mathrm{kg}$ xylasine. ${ }^{8}$ The rats in the control group were subjected to the same procedure with the exception that saline was substituted for Bleomycin. In treatment groups, the rats were treated with either Nicorandil (5 mg/kg; subcutaneously) or Sildenafil citrate $(10 \mathrm{ml} / \mathrm{kg}$; subcutaneously). Treatments were given 5 min after administration of Bleomycin and the treatment was continued for 28 consecutive days.

At the end of the experimental period, the rats were anaesthetized for blood collection from the retro-orbital sinus. The blood was centrifuged to separate serum and subjected to measure Lactate Dehydrogenase (LDH) as per the procedure using commercially available kits (Crest Biosystem, Goa). The animals were then euthanized; the thoracic cavity was exposed wash the lung with ice-cold physiological saline. For BALF collection, the lung was lavaged with ice-cold sterile physiological saline three times with a volume of $3 \mathrm{ml} /$ wash. The total numbers of cells in the BALF were counted with a hemocytometer. For differential counts of leukocytes in the BALF, smear slides were prepared and stained with Giemsa solution. Differential cell counts were obtained from a count of 300 cells per smear.Whole lungs were then rapidly excised, washed with ice-cold saline and dried. Lung tissues were homogenized in four volumes of ice-cold Tris- $\mathrm{HCl}$ buffer (50 millimolar, $\mathrm{pH} 7.4$ ) using a glass Teflon homogenizer (Tempest Virtishear, Model 278069; The Virtis Company, Gardiner, NY) after cutting the lung into small pieces with scissors (for $2 \mathrm{~min}$ at $5000 \mathrm{rpm}$ ). The homogenate was then centrifuged at $5000 \mathrm{rpm}$ for $60 \mathrm{~min}$ to remove debris. Clear upper supernatant fluid was taken and measurement of parameters was carried out.Lipid peroxidation or malondialdehyde (MDA) formation was determined by the method of Slater and Sawyer. ${ }^{6}$ Catalase (CAT) activity was detected by the method of Aebi's description ${ }^{7}$ and glutathione (GSH) was determined by the method of Moron et al. ${ }^{8}$ superoxide dismutase (SOD) was determined by the method of Misra and Fridovich. ${ }^{9}$ The hydroxyproline assay was performed as described by Edwards and O'Brien. ${ }^{10}$ Paraffinembedded lung specimens were cut into $5 \mu \mathrm{m}$ thick sections and stained with hematoxylin and eosin. The sections were examined under a light microscope for the presence of pathological changes and photomicrographs were taken. The pathologist was blinded to the animal treatment group.

\section{Statistical Analysis}

Results were expressed as mean \pm standard error of the mean. One-way analysis of variance, followed by Dunnett's multiple comparison tests (GraphPad Prism software for Windows, Version 5.01, GraphPad Software, Inc. 7825 Fay Avenue, Suite 230 La Jolla, CA 92037 USA) was used to analyze the statistical significance among different groups. The $P<0.05$ was considered to be statistically significant.

\section{RESULTS}

\section{BALF analysis Effect of Nicorandil on BALF Analysis in Bleomycin Induced Fibrotic Rats}

The total cell number was much higher in Bleomycin control group compared to control groups $(p<0.01)$. Treatment with Sildenafil and Nicorandil reduced the Bleomycin induced increase in total cell number in BALF. There were no statistical differences in the proportion of cells in BALF between BLM-Sildenafil and BLM-Nicorandil group [Table 1].

\section{Biochemical Analysis \\ Effect of Nicorandil on Lactate Dehydrogenase (LDH) in Bleomycin induced fibrotic Rats}

Lactate dehydrogrnase $(\mathrm{LDH})$ is one of the biochemical parameter which significantly found to have increased in the bleomycin control group after 28 days indicating the fibrosis due to alveolar damage. As evident compared with normal control/saline, the activities of LDH in serum is significantly increased in bleomycin treated fibrotic rats $(\mathrm{p}<0.001)$. Chronic administration of Nicorandil ( $5 \mathrm{mg} / \mathrm{kg}$,s.c.) markedly decreased the $\mathrm{LDH}$ activity when compared with bleomycin control $(\mathrm{p}<0.05)$. The activity was comparable with that of sildenafil $(10 \mathrm{mg} / \mathrm{kg}$, s.c.) treated group [Table 2].

\section{Lung Parameters \\ Malondialdehyde (MDA)}

MDA indicating the fibrosis due to lipid peroxidation was found to have significantly increased in the bleomycin control group after 28 days. Compared with normal control/saline, the levels of MDA in lungs significantly increased in bleomycin treated fibrotic rats $(\mathrm{p}<0.001)$. Chronic administration of nicorandil ( $5 \mathrm{mg} / \mathrm{kg}$, s.c.) markedly decreased the MDA activity in nicorandil treated when compared with bleomycin control $(\mathrm{p}<0.05)$. The activity was comparable with that of sildenafil $(10 \mathrm{mg} / \mathrm{kg}, \mathrm{s.c}$.$) treated group [Table 3].$

\section{Glutathione (GSH)}

$\mathrm{GSH}$, an antioxidant parameter, was found to have significantly decreased in the bleomycin control group after 28 days. This indicates the induction of pulmonary fibrosis due to increase lipid peroxidation. Compared with normal control/saline, the activities of GSH in lungs significantly decreased in bleomycin treated fibrotic rats $(\mathrm{p}<0.001)$. Chronic administration of nicorandil ( $5 \mathrm{mg} / \mathrm{kg}$, s.c.) markedly increased the GSH activity in nicorandil treated when compared with bleomycin control $(\mathrm{p}<0.05)$. The activity was comparable with that of sildenafil $(10 \mathrm{mg} / \mathrm{kg}$, s.c.) treated group [Table 3].

\section{Catalase (Cat)}

CAT was significantly found to have decreased in the bleomycin control group after 28 days indicating the fibrosis due to lipid peroxidation. Compared with normal control/saline, the activities of CAT in lungs significantly decreased in bleomycin treated fibrotic rats $(p<0.01)$. Chronic administration of nicorandil ( $5 \mathrm{mg} / \mathrm{kg}$,s.c.) markedly increased the CAT activity in nicorandil treated when compared with bleomycin control $(\mathrm{p}<0.05)$. The activity was comparable with that of sildenafil $(10 \mathrm{mg} / \mathrm{kg}$, s.c.) treated group [Table 3].

\section{Superoxide dismutase (SOD)}

SOD levels decrease with increase in lipid peroxidation due to induction of pulmonary fibrosis. This is evident by its significant decrease in the bleomycin control group after 28 days. Compared with normal control/ saline, the activities of SOD in lungs significantly decreased in bleomycin treated fibrotic rats $(\mathrm{p}<0.001)$. Chronic administration of nicorandil ( $5 \mathrm{mg} / \mathrm{kg}$, s.c.) markedly increased the SOD activity in nicorandil treated when compared with bleomycin control $(p<0.001)$. The activity was comparable with that of sildenafil $(10 \mathrm{mg} / \mathrm{kg}$, s.c.) treated group [Table 3].

\section{Nitrite Estimation (NO)}

NO levels were significantly decreased in the bleomycin control group after 28 days indicating the fibrosis and endothelial cell destruction. Compared with normal control/saline, the activities of NO in lungs significantly decreased in bleomycin treated fibrotic rats $(\mathrm{p}<0.001)$. 
Patel et al.: Anti-fibrotic potential of Nicorandil

Table 1: Effect of Nicorandil on Bronchoalveolar Lavage Fluid [BALF] Analysis inBleomycin Induced Fibrotic Rats

\begin{tabular}{lccc}
\hline \multicolumn{1}{c}{ Parameters } & $\begin{array}{c}\text { Total WBCs count } \\
\text { (cells per } \mu \mathrm{L} \text { ) }\end{array}$ & $\begin{array}{c}\text { Neutrophils } \\
\text { (cells per } \mu \mathrm{L} \text { ) }\end{array}$ & $\begin{array}{c}\text { Lymphocytes } \\
\text { (cells per } \mu \mathrm{L} \text { ) }\end{array}$ \\
\hline Normal Control & $575 \pm 75$ & $161.25 \pm 8.26$ & $357.5 \pm 21.74$ \\
Bleomycin Control & $2150 \pm 259.80^{*}$ & $873 \pm 37.22^{\star}$ & $1430 \pm 26.45^{*}$ \\
Bleomycin control treated with Sildenafil $(5 \mathrm{mg} / \mathrm{kg}$; s.c.) & $800 \pm 40.82 \#$ & $167.5 \pm 11.08 \#$ & $658.5 \pm 53.37 \#$ \\
Bleomycin control treated with Nicorandil $(5 \mathrm{mg} / \mathrm{kg}$; s.c.) & $800 \pm 21.28 \#$ & $180 \pm 24.15 \#$ & $526.5 \pm 46.46 \#$ \\
\hline
\end{tabular}

Values are given as Mean \pm SEM for groups of six rats each. Values are statistically significant at $\mathrm{p}<0.05$. Stastical significance was compared within the groups as follows: ${ }^{*}$ Bleomycin control rats were compared with normal control rats, \# Treated Bleomycin control rats were compared with Bleomycin control rats. SEM- Standard Error of Mean, WBCs: White blood cells

Table 2: Effect of Nicorandilon lactatede hydrogenase (LDH) levelin Bleomycin Induced fibrotic Rats

\begin{tabular}{lc}
\multicolumn{1}{c}{ Parameters } & LDH $(\mathrm{U} / \mathrm{mL})$ \\
\hline Normal Control & $1171.751 \pm 22.069$ \\
Bleomycin Control & $2149.362 \pm 111.045^{*}$ \\
Bleomycin control treated with Sildenafil $(5 \mathrm{mg} / \mathrm{kg} ;$ s.c.) & $1185.509 \pm 64.303^{*}$ \\
Bleomycin control treated with Nicorandil $(5 \mathrm{mg} / \mathrm{kg} ;$ s.c. $)$ & $1703.493 \pm 109.322^{*}$ \\
\hline
\end{tabular}

Values are given as Mean \pm SEM for groups of sox rats each. Values are statistically significant at $\mathrm{p}<0.05$. Stastical significance was compared within the groups as follows: * Bleomycin control rats were compared with normal control rats, \# Treated Bleomycin control rats were compared with Bleomycin control rats. SEM- Standard Error of Mean, WBCs: White blood cell

Table 3: Effect of Nicorandilon oxidant and anti-oxidant parameter in Bleomycin induced fibrotic Rats

\begin{tabular}{lccccc}
\hline \multicolumn{1}{c}{ Groups } & MDA & GSH & CAT & SOD & NO \\
\hline Normal Control & $6.092 \pm 2.489$ & $12.947 \pm 1.02$ & $55.916 \pm 8.35$ & $9.79 \pm 0.21$ & $19.54 \pm 1.59$ \\
Bleomycin Control & $124.5 \pm 19.04^{*}$ & $5.507 \pm 0.57^{*}$ & $20.70 \pm 1.89^{*}$ & $2.65 \pm 0.18^{*}$ & $7.37 \pm 1.03^{*}$ \\
Bleomycin control treated with Sildenafil (5mg/kg; s.c.) & $43.125 \pm 3.88^{*}$ & $9.95 \pm 0.641^{*}$ & $45.853 \pm 2.74^{*}$ & $8.26 \pm 0.17^{*}$ & $28.99 \pm 1.23^{*}$ \\
Bleomycin control treated with Nicorandil (5mg/kg; s.c.) & $78.09 \pm 8.65^{*}$ & $8.35 \pm 0.455^{*}$ & $45.703 \pm 3.76^{*}$ & $6.948 \pm 0.43^{*}$ & $25.37 \pm 0.61^{*}$ \\
\hline
\end{tabular}

Values are given as Mean \pm SEM for groups of sox rats each. Values are statistically significant at $p<0.05$. Stastical significance was compared within the groups as follows: ${ }^{*}$ Bleomycin control rats were compared with normal control rats, \# Treated Bleomycin control rats were compared with Bleomycin control rats. SEM- Standard Error of Mean. MDA: Malondialdehyde; GSH: Reduced Glutathione; CAT- Catalase; SOD- Superoxide Dismutase; NO- Nitrite

Table 4: Effect of Nicorandil on Hydroxyproline level in Bleomycin induced fibrotic Rats

\begin{tabular}{lc}
\hline \multicolumn{1}{c}{ Groups } & Hydroxyproline $(\mu \mathrm{g} / \mathrm{gm})$ \\
\hline Normal Control & $117.067 \pm 21.069$ \\
Bleomycin Control & $313.735 \pm 26.644^{*}$ \\
Bleomycin control treated with Sildenafil $(5 \mathrm{mg} / \mathrm{kg} ;$ s.c. $)$ & $149.852 \pm 16.282 \#$ \\
Bleomycin control treated with Nicorandil $(5 \mathrm{mg} / \mathrm{kg}$; s.c.) & $160.362 \pm 20.944 \#$ \\
\hline
\end{tabular}

Values are given as Mean \pm SEM for groups of sox rats each. Values are statistically significant at $\mathrm{p}<0.05$. Statistical significance was compared within the groups as follows: ${ }^{*}$ Bleomycin control rats were compared with normal control rats, \# Treated Bleomycin control rats were compared with Bleomycin control rats. SEM- Standard Error of Mean.

Chronic administration of nicorandil ( $5 \mathrm{mg} / \mathrm{kg}$, s.c.) markedly increased the NO activity in nicorandil treated when compared with bleomycin control $(\mathrm{p}<0.05)$. The activity was comparable with that of sildenafil $(10 \mathrm{mg} / \mathrm{kg}$, s.c.) treated group [Table 3].

\section{Hydroxylproline}

Hydroxyproline was significantly found to have increased in the bleomycin control group after 28 days indicating the fibrosis due to collagen depo- sition. As evident in table no.6, compared with normal control/saline, the level of Hydroxyproline in lungs significantly decreased in bleomycin treated fibrotic rats $(\mathrm{p}<0.001)$. Chronic administration of nicorandil ( $5 \mathrm{mg} / \mathrm{kg}$, s.c.) markedly decreased the Hydroxyproline level in nicorandil treated when compared with bleomycin control $(\mathrm{p}<0.01)$. The activity was comparable with that of sildenafil $(10 \mathrm{mg} / \mathrm{kg}$, s.c.) treated group [Table 4]. 

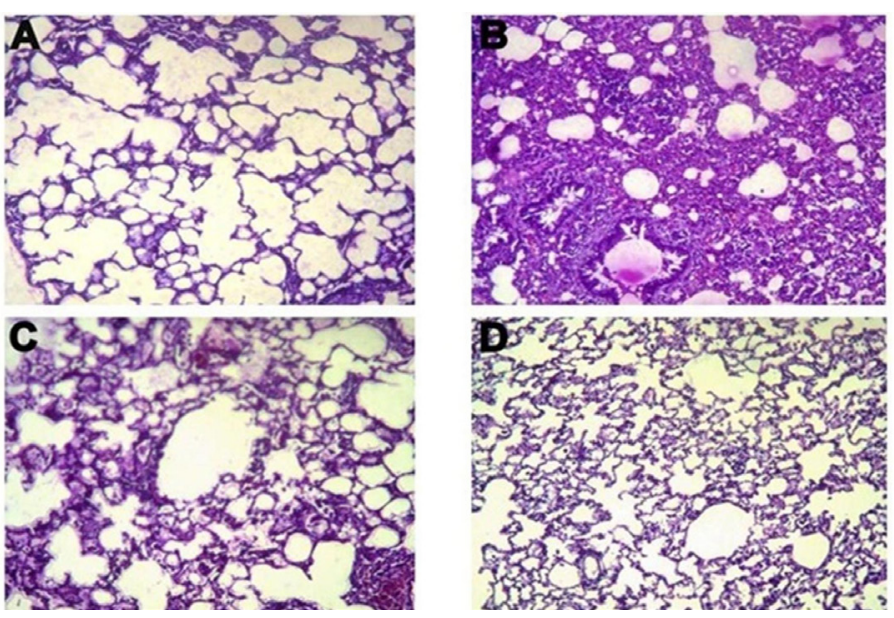

Figure 1: Effect of Nicorandil on histological change of lung tissue in Bleomycin induced fibrotic rats. (A) Normal control/saline - lung showing normal architecture including normal lung parenchyma and alveolar spaces, (B) Bleomycin treated-collapse of alveolar spaces, marked thickening in alveolar septa, a large number of leukocytes accumulated in alveolar walls and proliferation of fibroblasts, (C) Bleomycin-Sildenafil treated and (D) BleomycinNicorandil treated-less marked collapsed alveolar spaces, less infilterated cells.

\section{Lung Histopathology}

Lungs of the normal control rats showed normal alveolar spaces and normal thickening of alveolar septa. The lungs of rats treated with bleomycin showed extensive inflammation and fibrosis, collapsed alveoli, marked thickening of the interalveolar septa, and dense interstitial infiltration by inflammatory cells mainly lymphocytes, neutrophils, and fibroblasts and rats treated with both BLM and Nicorandil showed marked suppression of the bleomycin-induced inflammatory cellular infiltration as evidenced by reduced thickening of the interalveolar septa and more inflation of the alveoli [Figure 1].

\section{DISCUSSION}

Idiopathic pulmonary fibrosis (IPF) is a chronic inflammatory interstitial lung disease with a high mortality rate and poor response to available medical therapy. ${ }^{11,12}$ Bleomycin, a glycopeptide antibiotic, is generally used in the treatment of lymphomas, squamous cell carcinoma and testicular tumors. However, the effective use of bleomycin in chemotherapy is greatly limited, since it causes interstitial pulmonary fibrosis. In addition, several studies have demonstrated that bleomycin administration in rats decreased the anti-oxidative capacity and increased oxidative stress in the lung tissue, which aggravated pulmonary fibrosis. ${ }^{13,14,15}$

It has been established that in bleomycin induced pulmonary fibrosis the levels of the biochemical, oxidant and antioxidant parameters changed significantly than those of the normal levels. This is evident by increased levels Lactate Dehydrogenase ( $\mathrm{LDH})$ which is a marker of biochemical index. Also the levels of malondialdehyde (MDA) are found to increase which is an oxidant parameter. While those of Superoxide Dismutase (SOD), Glutathione (GSH), Catalase (CAT), free NO levels decreased which are indicative of oxidative stress.

Imbalance between oxidant and antioxidant defence mechanisms is contributed to the incidence of pulmonary fibrosis. Nicorandil decreased the LDH levels indicating prevention of cell injury and hence preventing pulmonary fibrosis. Also the levels of MDA were found to decrease by Nicorandil treatment which indicates that lipid peroxidation and hence the cell damage has been reduced. Moreover, the reduced levels of SOD,
GSH and CAT followed by the treatment with nicorandil depicting the protective role of it against the cell damage caused by reactive oxygen species in pulmonary fibrosis. Nitric oxide (NO) has been localized and identified as two different forms, i.e. a constitutive form present in endothelial cells and brain and an inducible form found in macrophages. The reduction in total NO levels seen in bleomycin administration could be due to quenching of NO directly by superoxide to form peroxynitrite which is demonstrated to be present in the inflammatory lesions of acute lung injury. In addition, nitric oxide production may enhance transforming growth factor- $\alpha$ activity, which is proven a strong stimulator of collagen, fibronectin, and proteoglycan synthesis. ${ }^{17,18}$ The levels of NO were increased at significant extent followed by nicorandil treatment which may explain the probable mechanism of Nicorandil. The increased levels of Nitric Oxide (NO) are coupled with its vasodilatory action that could ameliorate the pulmonary hypertension which would be the potential triggering factor to cause pulmonary fibrosis. The levels of Hydroxyproline, a marker of collagen index, were decreased significantly by Nicorandil which indicates the prevention of fibrosis and alveolar damage.

The preventive effect of nicorandil may reflect the reduction in the migration of neutrophils and other inflammatory cells in the inflamed region, thereby mitigating tissue damage in the lung. The possible mechanism might be one whereby nicorandil may repress reactive oxygen radicals through scavenging them, thereby decreasing neutrophil recruitment into the lungs. Previous studies demonstrated that anti-oxidant agents ameliorated the accumulation of leukocytes in bronchial lavage fluid and lung tissue which agrees with our findings. ${ }^{12-19}$

The pathophysiology of Bleomycin-induced lung injury typically consisted of two overlapping stages; an early inflammatory phase characterized by leukocyte infiltration and injury to alveolar epithelial cells, and a subsequent fibro-proliferative phase with matrix remodeling and fibrosis. ${ }^{20}$ Haematoxylin \& Eosin (H\&E) staining results in BLM control group showed that acute inflammations were prominent with moderate or severe hemorrhage, widened alveolar septa, and infiltration of numerous inflammatory cells predominated by macrophages, neutral granulocytes, and lymphocytes. The extent of fibrosis in nicorandil treated group was mild. These results suggest that nicorandil partially alleviates the extent of both alveolitis and PF induced by BLM in rats due to reductions in inflammatory cell infiltration and collagen fiber accumulations in lungs from rats with PF.

Our results together with biochemical and morphological data agree with this hypothesis, since bleomycin induced increase in fibrotic activity, as assessed by the lung collagen content, is also reduced by nicorandil treatment. This finding suggests that nicorandil has an additional protective effect on inflammation-induced production and deposition of extracellular matrix components, which may be useful in preventing pulmonary fibrosis. Previously, it was reported that nicorandil had protective action against the monocrotaline induced endothelial damage in PAH. ${ }^{5}$ Consistent with our findings, nicorandil has also been shown to prevent injury ensued by oxidative situations as pulmonary arterial hypertension (PAH) which is one the predisposing factor for the occurrence of pulmonary fibrosis. Decreased production of vasodilator substances such as nitric oxide (NO) has been involved in the PAH. ${ }^{21}$ It is established that Nicorandil exerts its major effects attributing to potassium channel opening and with adjunctive NO releasing property which is used in the $\mathrm{PAH}$ treatment. These properties may be contributed to its protective role in pulmonary fibrosis. Hence, we support the hypothesis that Nicorandil, A potassium channel opener, may be exploited as an anti fibrotic agent for the prevention of bleomycin induced pulmonary fibrosis, by its antioxidant activity. 


\section{CONCLUSION}

The present study confirms that oxidative stress increased the fibroblast deposition contributing to the induction of pulmonary fibrosis. In addition, the ability of Nicorandil to prevent the oxidative stress by antioxidant property and also to prevent fibrosis by preventing collagen deposition might be of therapeutic relevance. Hence, Nicorandil may be used to prevent the pulmonary fibrosis by $\mathrm{K}^{+}$mediated NO release.

\section{ACKNOWLEDGEMENT}

Authors are thankful to Principal, A.R. and G.H. Patel Institute of Pharmacy for providing necessary infrastructural and instrumental facility to execute the research work.

\section{CONFLICT OF INTEREST}

Authors do not have any conflict of interest.

\section{ABBREVIATION USED}

LDH levels: Serum Lactate Dehydrogenase; BALF: Broncho-alveolar Lavage fluid; GSH: Glutathione; CAT: Catalase; SOD: Superoxide Dismutase; NO: Nitric Oxide; eNOS: endothelial NO synthase; VIP: Vasoactive Intestinal Peptide; ATP: Adenosine triphosphate; KATP: sensitive potassium; eNOS: endothelial NO synthase; L-NAME: N-Nitroarginine methyl ester; MDA: Malondialdehyde; GSH: Reduced Glutathione; CAT: Catalase; SOD: Superoxide Dismutase; NO: Nitrite; H\&E: Haematoxylin \& Eosin; PAH: Pulmonary arterial hypertension.

\section{REFERENCES}

1. Yildirim A, Ersoy Y, Ercan F, Atukeren P, Gumustas K, et al. Phosphodiesterase-5 inhibition by sildenafil citrate in a rat model of bleomycin-induced lung fibrosis. Pulmonary pharmacology \& therapeutics. 2010;23(3):215-21. https://doi. org/10.1016/j.pupt.2009.11.002; PMid:19945540.

2. Kotlikoff MI, Kamm KE. Molecular mechanisms of beta-adrenergic relaxation of airway smooth muscle. Annual Review of Physiology. 1996;58(1):115-41. https://doi.org/10.1146/annurev.physiol.58.1.115; https://doi.org/10.1146/annurev. ph.58.030196.000555; PMid:8815788.

3. Cunha JF, Campestrini FD, Calixto JB, Scremin A, Paulino N. The mechanism of gentisic acid-induced relaxation of the guinea pig isolated trachea: the role of potassium channels and vasoactive intestinal peptide receptors. Brazilian Journal of Medical and Biological Research. 2001;34(3):381-8. https://doi.org/10.1590/ S0100-879X2001000300013; PMid:11262590.

4. Ghatta S, Nimmagadda D, Xu X, O'rourke ST. Large-conductance, calciumactivated potassium channels: structural and functional implications. Pharmacology \& therapeutics. 2006;110(1):103-16. https://doi.org/10.1016/j.pharmther a.2005.10.007PMid:16356551

5. Sahara M, Sata M, Morita T, Hirata Y, Nagai R. Nicorandil attenuates monocrotaline-induced vascular endothelial damage and pulmonary arterial hypertension. PLoS One. 2012;7(3):e33367. https://doi.org/10.1371/journal.pone.0033367;
PMid:22479390 PMCid:PMC3316574.

6. Slater TF, Sawyer BC. The stimulatory effects of carbon tetrachloride and other halogenoalkanes on peroxidative reactions in rat liver fractions in vitro. General features of the systems used. Biochemical Journal. 1971;123(5):805-14. https:// doi.org/10.1042/bj1230805; https://doi.org/10.1042/bj1230815; https://doi.org/ 10.1042/bj1230823; PMid:4399399 PMCid:PMC1177080.

7. Aebi H. [13] Catalase in vitro. Methods in enzymology. 1984;105:121-6. https:// doi.org/10.1016/S0076-6879(84)05016-3

8. Moron MS, Depierre JW, Mannervik B. Levels of glutathione, glutathione reductase and glutathione S-transferase activities in rat lung and liver. Biochimica et Biophysica Acta (BBA)-General Subjects. 1979;582(1):67-78. https://doi. org/10.1016/0304-4165(79)90289-7

9. Misra HP, Fridovich I. The role of superoxide anion in the autoxidation of epinephrine and a simple assay for superoxide dismutase. Journal of Biological chemistry. 1972;247(10):3170-5. PMid:4623845.

10. Edwards CA, O'Brien WD. Modified assay for determination of hydroxyproline in a tissue hydrolyzate. Clinica chimica acta. 1980;104(2):161-7. https://doi. org/10.1016/0009-8981(80)90192-8.

11. Walter N, Collard HR, King Jr TE. Current perspectives on the treatment of idiopathic pulmonary fibrosis. Proceedings of the American Thoracic Society. 2006;3(4):330-8. https://doi.org/10.1513/pats.200602-016TK; PMid:16738197.

12. Akgedik R, Akgedik $S$, Karamanlı $H$, Uysal $S$, Bozkurt B, et al. Effect of resveratrol on treatment of bleomycin-induced pulmonary fibrosis in rats. Inflammation. 2012;35(5):1732-41. https://doi.org/10.1007/s10753-012-9491-0; PMid:22707284.

13. Samah M, El-Aidy AE, Tawfik MK, Ewais MM. Evaluation of the antifibrotic effect of fenofibrate and rosiglitazone on bleomycin-induced pulmonary fibrosis in rats. European journal of pharmacology. 2012;689(1):186-93. https://doi. org/10.1016/j.ejphar.2012.05.026; PMid:22659583.

14. Razavi-Azarkhiavi K, Ali-Omrani M, Solgi R, Bagheri P, Haji-Noormohammadi M, et al. Silymarin alleviates bleomycin-induced pulmonary toxicity and lipid peroxidation in mice. Pharmaceutical biology. 2014;52(10):1267-71. https://doi.org/10. 3109/13880209.2014.889176; PMid:25026360

15. Zhang K, Si XP, Huang J, Han J, Liang X, et al. Preventive Effects of Rhodiola rosea L. on Bleomycin-Induced Pulmonary Fibrosis in Rats. International journal of molecular sciences. 2016;17(6):879. https://doi.org/10.3390/ijms17060879; PMid:27271612 PMCid:PMC4926413.

16. Hay J, Shahzeidi S, Laurent G. Mechanisms of bleomycin-induced lung damage. Archives of toxicology. 1991;65(2):81-94. https://doi.org/10.1007/BF02034932 PMid:1711838

17. Punithavathi $D$, Venkatesan N, Babu M. Curcumin inhibition of bleomycin-induced pulmonary fibrosis in rats. British journal of pharmacology. 2000;131(2):169-72. https://doi.org/10.1038/sj.bjp.0703578; PMid:10991907 PMCid:PMC1572330.

18. Gow AJ, Thom SR, Ischiropoulos H. Nitric oxide and peroxynitrite-mediated pulmonary cell death. American Journal of Physiology-Lung Cellular and Molecular Physiology. 1998;274(1):L112-8.

19. Sriram N, Kalayarasan S, Sudhandiran G. Epigallocatechin-3-gallate augments antioxidant activities and inhibits inflammation during bleomycin-induced experimental pulmonary fibrosis through Nrf2-Keap1 signaling. Pulmonary pharmacology \& therapeutics. 2009;22(3):221-36. https://doi.org/10.1016/j. pupt.2008.12.010; PMid:19138753.

20. Reinert T, Baldotto CS, Nunes FA, Scheliga AA. Bleomycin-induced lung injury. J Cancer Res 2013;2013:1-9. https://doi.org/10.1155/2013/480608.

21. Baliga RS, Milsom AB, Ghosh SM, Trinder SL, MacAllister RJ, Ahluwalia A, Hobbs AJ. Dietary Nitrate Ameliorates Pulmonary HypertensionClinical Perspective. Circulation. 2012;125(23):2922-32. https://doi.org/10.1161/CIRCULATIONAHA.112.100586; PMid:22572914 PMCid:PMC3502837. 